\title{
Survey method choice for wildlife management: the case of moose Alces alces in Sweden
}

\author{
Johan Månsson, Cindy E. Hauser, Henrik Andrén \& Hugh P. Possingham
}

We need to monitor wildlife populations to determine whether management goals are achieved and to improve future decisions. Therefore, it is important to evaluate the cost and accuracy of monitoring strategies in the context of management. Using a computer simulation of a harvested population, we tested the relative performance of three survey methods: aerial survey, pellet-group counts and hunters' observations, to inform about the management of Swedish moose Alces alces populations. Where more than one survey method was used in a single year, we used Bayes' theorem to combine information and estimate population size. We used two measures of performance: the fraction of time in which the population had an 'undesirable' size and inter-annual variation in harvest. Furthermore, we traded these performance measures against their cost. An annual aerial survey was the most costly monitoring method $(27,000 €)$ and maintained the population within the desired range $72 \%$ of the time. The least expensive monitoring strategy (hunters' observations; $1,600 €$ ) maintained the population within a desired range of $66 \%$ of the time. A combination of two relatively inexpensive survey methods (i.e. pellet-group counts and hunters' observations; at an expense of $10,000 €$ ) maintained the population within the desired range in $76 \%$ of the simulated years. Thus, a combination of annual pellet-group counts and hunters' observations performed better than annual aerial surveys, but was considerably less expensive. Furthermore, the annual combination of pellet-group counts and hunters' observations also performed best regarding the inter-annual harvest variation. Management actions only maintained the population within the desired range $81 \%$ of the time, even when population size was observed without error, mainly due to variable net growth rates. In wildlife management systems, where a variety of monitoring methods are used, the overall performance generally improves with monitoring expenditure, but very few studies explicitly account for expenditure. However, our study shows that combinations of inexpensive methods can reduce monitoring costs substantially while yielding an equal or an increased performance.

Key words: aerial counts, Bayesian updating, direct observations, pellet-group counts, simulation, surveys, trade-off, ungulate

Johan Månsson \& Henrik Andrén, Grimsö Wildlife Research Station, Department of Ecology, Swedish University of Agricultural Sciences, SE-730 91 Riddarhyttan, Sweden-e-mail addresses: johan.mansson@.slu.se (Johan Månsson); henrik.andren@slu.se (HenrikAndrén)

Cindy E. Hauser* \& Hugh P. Possingham, University of Queensland, The Ecology Centre and School of Integrative Biology, Brisbane 4072 QLD, Australia-e-mail addresses: chauser@unimelb.edu.an (CindyE.Hauser); h.possingham@ uq.edu.an (Hugh P. Possingham)

*Present address: Australian Centre of Excellence for Risk Analysis, University of Melbourne, VIC 3010, Australia

Corresponding author: Johan Månsson

Received 10 May 2010, accepted 2 February 2011

Associate Editor: Stefano Focardi

Management of wildlife populations demands reliable monitoring methods to provide feedback on whether or not goals are currently being achieved and to ensure that goals will be met in the future. This has prompted ecologists and managers to ask: how reliable and accurate must our monitoring be 
to achieve our goals? How do we trade the cost of monitoring against the cost of making a bad management decision? Such questions apply to a broad range of wildlife management problems from conservation (Yokomizo et al. 2004, Chades et al. 2008) to invasive species control (Rout et al. 2009, Hauser \& McCarthy 2009) and harvesting (Gerber et al. 2005, Hauser et al. 2006). The need for accurate estimates of population size might depend on the likely state of the population in relation to the set goals; e.g. less accurate estimates of population size (or indicators of population size) may be acceptable when a population is thought to be in a desirable state and likely to remain so (Hauser et al. 2006).

To illustrate our trade-off approach to finding the most appropriate monitoring strategy in the context of population management, we investigate a variety of monitoring strategies (combinations of survey methods) for a moose Alces alces population. Apart from insights into the performance and cost of combinations of different survey methods within the management of moose, our study provides an approach to choosing the best monitoring strategy for which several methods are available. We wonder how useful it is, in methodological studies, to consider the accuracy of monitoring methods without simultaneously considering their cost and impact on the management outcomes (see Bowden et al. 2000 for exception).

For large mammals, several survey methods have been developed and used to estimate population size, both by using indices and direct counts (Caughley \& Sinclair 1994). However, the methods vary with respect to their accuracy (Timmerman 1974, Ericsson \& Wallin 1999, Barnes 2001, Campbell et al. 2004) and cost (Smits et al.1994, Campbell et al. 2004, Garel et al. 2005). Aerial surveys are frequently used for estimating population densities and trends for large mammals (Timmerman 1974, Jachmann 2002), but they make up an expensive option (Rönnegård et al. 2008). Two cheaper methods used to estimate large mammal populations are pellet-group counts (Neff 1968) and direct observations, e.g. made by hunters (Timmerman 1974, Haagenrud et al. 1987). These two methods differ from aerial surveys (where a reliable correction factor for sightability is available) in that they result in an indirect measure of moose abundance; i.e. an index of the number of animals. The transformation from these indices to absolute numbers is an additional step that increases the potential error connected with the estimates (Neff 1968, Andersen et al. 1992, Solberg \& Sæther 1999). Both linear and non-linear relationships have been found between population size estimates from pellet-group counts and other independent methods (Jordan et al. 1993, Mandujano \& Gallina 1995, McIntosh et al. 1995, Barnes 2001, Rönnegård et al. 2008). Direct observations using standardised protocols, e.g. hunters' observations, have shown linear relationships with animal densities estimated using other survey methods (true population size in enclosures; Vincent et al. 1996, or aerial survey; Ericsson \& Wallin 1999, cohort analyses; Solberg \& Sæther 1999, Rönnegård et al. 2008 and DNAcapture mark recapture; Kindberg et al. 2009).

The moose harvest quotas in Sweden are determined annually at the county level for small hunting areas (Wennberg DiGasper 2006) or as a 3-year management plan determined by the landowners and hunters within specific 'moose management units' (Wennberg DiGasper 2006). The costs and benefits of Swedish moose management include damage to forestry (Lavsund et al. 2003), vehicle collisions (Seiler 2003) and profit from harvest (Mattsson 1990). Therefore, a reasonable management goal is to keep the moose population below an upper limit to avoid costs, and above a lower limit to maintain an acceptably large harvest. Given that the harvesting quotas are driven by the population estimate, the critical question is: which method(s) should be used for monitoring so that harvesting can maintain the population at an acceptable level without excessive monitoring costs?

In our study, we used a simulation model of regional moose population dynamics in Sweden, parameterised with field data, to evaluate the management performance of different monitoring strategies. We used data from empirical surveys to estimate the accuracy of the three survey methods: aerial surveys, pellet-group counts and hunters' observations. We used different combinations of the three survey methods to predict the population size, with some uncertainty, which in turn determines the quota and, hence, the number of moose in the stochastic simulation model. The performance of each monitoring strategy was determined according to two criteria: how often the population size is within desirable limits and the inter-annual variation in harvest. Furthermore, we related management performance to the monitoring costs, a factor invariably ignored in the classical monitoring literature. 


\section{Material and methods}

\section{Moose management in Sweden}

The management objective within Swedish moose management is most often set in absolute numbers. Post-hunting densities vary between 0.7 and 1.3 moose $/ \mathrm{km}^{2}$ in most parts of Sweden (Lavsund et al. 2003). The primary objective in our study was to maintain the post-hunting density at $1.0 \mathrm{moose} / \mathrm{km}^{2}$ by regulating harvest. We considered a management area of about $1,000 \mathrm{~km}^{2}$ and, thus, the target population size is 1,000 individuals after harvesting. This is actually much larger than the median moose management area in Sweden (Wennberg DiGasper 2006), but the current policy for interest groups involved in moose management is aiming at moose management areas of at least $500 \mathrm{~km}^{2}$ (Anon. 2007). Furthermore, Sylvén (2000) proposed that hunters' observations should be used in sampling areas $>500 \mathrm{~km}^{2}$. Given the fluctuations inherent in moose population size, e.g. annual variation in reproduction and survival, it is unrealistic to judge management as successful only when there are precisely 1,000 moose. Hence, we defined population sizes between 800 and 1,200 individuals to be acceptable.

The exact population size cannot be known with certainty, so we used a probability distribution to describe which population sizes are plausible on the basis of the current information. We used a combination of aerial counts, pellet group counts and/or hunters' observations to derive the probability distribution for the population size. We assessed different strategies for combining survey methods by simulating the process of moose population measurement, harvest and growth.

\section{Measuring population size}

In our study, we did not focus on hunting as the management action, but on the variety of survey methods available to the manager to determine the annual harvest quota. Below we describe our models for converting survey data to a probability distribution for population size.

\section{Aerial counts}

A commonly used method in Sweden is to sample plots of $2 \times 2 \mathrm{~km}$ that are systematically distributed and surveyed using helicopter; usually $25-30 \%$ of the total area is surveyed. About $30 \%$ of the sample plots are resampled to correct for moose sightability (see methodology for aerial count in year 2006; Rönnegård et al. 2008). We followed the prerequisites for minimising the risk of undercounting bias in aerial counts by e.g. only surveying large animals one species at a time, use of helicopter and doublecounts techniques (Jachmann 2002).

The corrected mean number of moose/sampling plot was 4.73 ( $\pm 0.50 \mathrm{SE})$, which corresponds to 1.18 $\left( \pm 0.125 \mathrm{SE}\right.$ ) moose $/ \mathrm{km}^{2}$ (from an aerial survey in 2006 at Grimsö; see also Rönnegård et al. 2008). The error (SE) includes both the measurement error of sampling of moose and the measurement error of the correction factor for sightability $(73 \%)$. Thus, the observed number of moose was corrected with an estimated factor for sightability to obtain an absolute estimate of the moose numbers. For a population of 1,000 individuals, i.e. the target size, this corresponds to a standard error of 106 individuals (Table 1). Hence, when we simulated aerial surveys, we drew the estimated population size from a normal probability distribution whose mean is the true population size and a standard error of 106 (see Table 1).

\section{Pellet-group counts}

Moose pellet groups are usually counted during spring (late April - early May). Only pellet groups from the previous winter are counted, and they are aged by their appearance, colour and the position in relation to leaf litter and old vegetation (Neff 1968).

We assumed that pellet groups are counted within

Table 1. Properties of each survey method.

\begin{tabular}{lccc}
\hline & Aerial survey & Pellet-group count & Hunters' observations \\
\hline Sample size & $84 \times 4 \mathrm{~km}^{2}$ & $1,200 \times 100 \mathrm{~m}^{2}$ & 1,575 hunters $\times$ days \\
Total cost (in $€)$ & 27,000 & 8,400 & 1,600 \\
$\mathrm{a}$ & - & 0 & 0.2151 \\
$\mathrm{~b}$ & - & $3.66 \times 10^{-4}$ & $2.96 \times 10^{-4}$ \\
$\sigma_{\mathrm{I}}$ & - & 0.05 & 0.0424 \\
SE around population estimate & $106^{\mathrm{a}}$ & $125^{\mathrm{b}}$ & $143^{\mathrm{b}}$ \\
\hline
\end{tabular}

a Taken from past aerial survey analysis at Grimsö.

${ }^{\mathrm{b}}$ Calculated as $\sigma_{\mathrm{I}} / \mathrm{b}$. 
1,200 plots (of $100 \mathrm{~m}^{2}$ each) distributed over the management area (see Table 1). We calculated the measurement error (SE) around these counts from a systematically distributed pellet-group count conducted around the Grimsö wildlife research area in 2006 (Månsson et al. 2007). The mean number of pellet groups/plot was $0.4322( \pm 0.043 \mathrm{SE})$, which corresponded to a moose density of $1.18( \pm 0.125$ SE) moose $/ \mathrm{km}^{2}$ estimated from an aerial survey in the same year. This corresponds to a defecation rate of 18.3 ( $\pm 2.8 \mathrm{SE}$ ) pellet groups/day assuming an accumulation period of 200 days (i.e. during October-April, with a very low activity of vegetation and decomposers).

Pellet-group counts are an indirect index of the population size. To set a harvest quota each year, we require an estimate of total population and, therefore, we need a method of converting pellet-group counts into moose numbers. We must establish not only the measurement error associated with pelletgroup counts, but also the relationship between this index and the moose population size. Based on other studies performed in areas comparable to the Grimsö wildlife research area, we assumed a linear relationship between observed pellet-group counts and the best available estimation of population size (Appendix I) using: $I=a+b N+\varepsilon$, where $I$ is the mean number of moose pellet groups found within the 100 $\mathrm{m}^{2}$ plots, $\mathrm{N}$ is the moose population size (postharvest) within an area of $1,000 \mathrm{~km}^{2}$ and $\varepsilon$ is the noise in the relationship, assumed to be normally distributed with mean 0 and variance $\sigma_{I}^{2}$. We estimated the model parameters $\mathrm{a}, \mathrm{b}$ and $\sigma_{\mathrm{I}}$ from the mean number of pellet groups/plot (0.4322) and the density of moose around the Grimsö wildlife research area in 2006 (1.18 moose $/ \mathrm{km}^{2}$ from aerial survey or 1,180 moose in a management area of $1,000 \mathrm{~km}^{2}$ ), assuming that $\mathrm{a}=0$ then $\mathrm{b}=0.4322 / 1180$ $=3.66 \times 10^{-4}$ (see Table 1) and the correlation coefficient $r=0.90$ (Neff 1968, Barnes 2001; see Appendix I) within the range of $600-1,400$ moose. When pellet-group counts are simulated, we drew the observed count from a normal distribution with mean $\mathrm{a}+\mathrm{b} \mathrm{N}$ and variance $\sigma_{\mathrm{I} 2}$.

When a manager observes the mean number of pellet-groups found (I), he/she must convert it to a probability distribution for likely population size. Given the linear relationship we have assumed that between pellet-group counts and moose population size, it can be shown that an observed count I generates a normal probability distribution for likely population size, with mean (I - a)/b and variance
$\sigma_{I 2} / b^{2}$ (see Appendix II for derivation). The mean is an intuitive rearrangement of the linear function, and the variance takes into account both the measurement error associated with observing pellet-group counts and the noise in the relationship between the pellet-group counts and the population size.

\section{Hunters' observations}

During the first week of the moose hunt, each hunting team voluntarily records the number of moose observed from selected hunting spots to achieve an annual relative index of moose population size (Ericsson \& Wallin 1999). The hunters also record the numbers of hunters each day (Ericsson \& Wallin 1999). In our study, we assumed that there are 15 moose hunting teams with 15 members in each team within the management area generating a sample size of 1,575 hunter days (see Table 1). We estimated the model parameters $\mathrm{a}, \mathrm{b}$ and $\sigma_{\mathrm{I}}$ using data in Solberg \& Sæther (1999; see Appendix I). Like pellet-group counts, hunters' observations are an index for population size, and we used a linear relationship between population size and the number of moose observations/hunter day to convert the index to a probability distribution for population size (see Appendix I and Table 1).

\section{Combining information from multiple surveys}

To describe the likely population size each year, we used the discrete probability distribution:

$\operatorname{Pr}\left(\mathrm{N}_{\mathrm{t}}=\mathrm{n}_{\mathrm{i}}\right), \mathrm{n}_{\mathrm{i}}=0,50,100, \ldots, 8000$, where $\mathrm{N}_{\mathrm{t}}$ is the true post-harvest population size in year $t$. The probability distributions referred to above are continuous, so we allocated probability to discrete classes by setting boundaries on the classes (i.e. (0, $25),(25,75),(75,125), \ldots,(7975, \infty))$ and integrating the continuous distributions over the class limits. When the relevant normal distribution allocated probability to a negative population size, we ignored it and renormalised the probability distribution over the non-negative classes.

When more than one survey method is carried out in a year, Bayes' theorem can be used to combine information in the following way:

$$
\begin{gathered}
\operatorname{Pr}\left(\mathrm{N}_{\mathrm{t}}=\mathrm{n}_{\mathrm{i}} \mid \mathrm{O}_{1}, \mathrm{O}_{2}\right)=\frac{\mathrm{f}\left(\mathrm{O}_{2} \mid \mathrm{N}_{\mathrm{t}}=\mathrm{n}_{\mathrm{i}}\right) \operatorname{Pr}\left(\mathrm{N}_{\mathrm{t}}=\mathrm{n}_{\mathrm{i}} \mid \mathrm{O}_{1}\right)}{\mathrm{K}} \\
\text { for } \mathrm{n}_{\mathrm{i}}=0,50, \ldots, 8000
\end{gathered}
$$

where $\mathrm{O}_{1}$ and $\mathrm{O}_{2}$ are the observations obtained from each survey method and $\mathrm{K}$ is a normalising constant which ensures that 


$$
\sum_{\mathrm{i}=1}^{161} \operatorname{Pr}\left(\mathrm{N}_{\mathrm{t}}=\mathrm{n}_{\mathrm{i}} \mid \mathrm{O}_{1}, \mathrm{O}_{2}\right)=1
$$

The order in which the monitoring methods are used to update the distribution does not affect the final probability distribution for likely population size. If probability distributions derived from different approaches show consistent results, then belief in the most likely values will be reinforced. If there is disparity between the approaches, then the weighting of each approach in the final distribution will reflect the relative uncertainty (variance) surrounding the mean.

An example of the combination of hunters' observation and pellet-group counts to obtain a probability distribution for population size is shown in Figure 1. The underlying population has 800 individuals, which generates a mean pellet-group count of 0.3291 groups/plot and hunter observations of 0.4440 individuals/hunting day. In isolation, the pellet-group count would predict an expected population size of 899 individuals with a standard deviation of 137, whereas the hunters' observations would predict an expected population size of 773 individuals with a standard deviation of 143. Combined, they predict an expected population size of 839 individuals with a standard deviation of 99 . While the combined measure overestimates the actual population size, it has a higher precision than can be generated from either survey method on its own.

\section{Monitoring costs}

The costs for the three survey methods were estimated from field work conducted around the

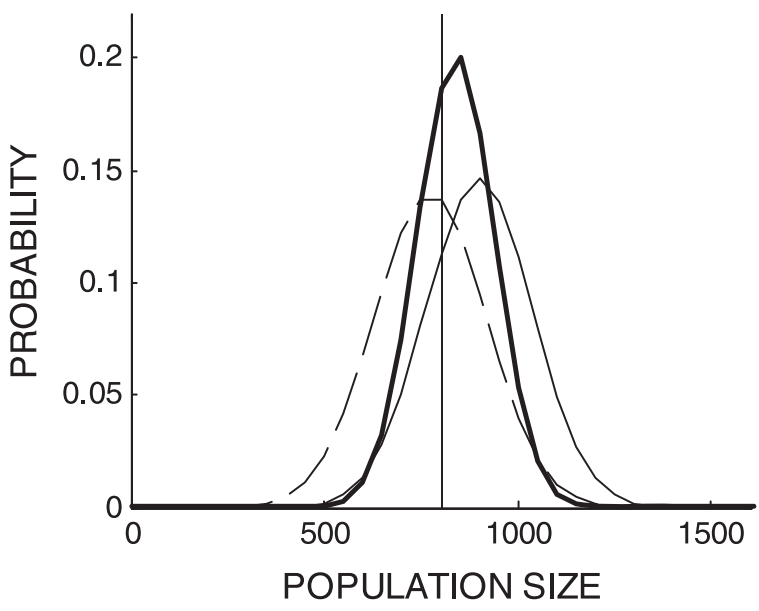

Figure 1. An example of combining pellet-group counts and hunters' observations to measure the likely population size. The true underlying population size is 800 individuals (indicated by the vertical line), and a mean pellet-group count of 0.3291 groups/plot gives an expected population size of 899 individuals with a standard deviation of 137 (thin solid line), and hunters' observations of 0.4440 (moose/hunter days) gives an expected population size of 773 individuals with a standard deviation of 143 (dashed line). The combined distribution has a mean of 839 individuals and a standard deviation of 99 (thick solid line).

Grimsö research area during 2004-2006 (Månsson et al. 2007, Rönnegård et al. 2008). The total costs for the aerial count was about $27,000 €$, for pellet counts $8,400 €$ and for hunters' observations $1,600 €$ (Table 2).

\section{The population model}

In order to assess our monitoring strategies over time, we simulated the underlying moose population dynamics as well as the manager's decisions. Thus, we used a stochastic population model to describe changes in the post-harvest population size

Table 2. Detailed breakdown of estimated costs (in $€$ ) during the three field surveys.

\begin{tabular}{|c|c|c|c|c|c|c|c|c|}
\hline \multicolumn{3}{|c|}{ Aerial count } & \multicolumn{3}{|c|}{ Pellet-group count } & \multicolumn{3}{|c|}{ Hunters' observation } \\
\hline & $\begin{array}{c}\text { Time } \\
\text { in hours }\end{array}$ & Costs & & $\begin{array}{c}\text { Time } \\
\text { in hours }\end{array}$ & Costs & & $\begin{array}{c}\text { Time } \\
\text { in hours }\end{array}$ & Costs \\
\hline Helicopter 70 plots $*$ & 35 & 14,200 & 1200 plots & 240 & $6,000, \alpha$ & $\begin{array}{c}\text { Distribution of } \\
\text { survey forms }\end{array}$ & - & 100 \\
\hline Helicopter 21 plots $* *$ & 11 & 4,500 & Travel,$\not \varnothing$ & - & 1,000,ðరం & & & \\
\hline Helicopter ferry $* * *$ & 12 & 4,800 & & & & & & \\
\hline Labour field assistant & 80 & 2,000 & & & & & & \\
\hline Data entry and analysis & 60 & 1,500 & $\begin{array}{l}\text { Data entry and } \\
\text { analysis }\end{array}$ & 60 & 1,500 & $\begin{array}{l}\text { Data entry and } \\
\text { analysis }\end{array}$ & 60 & 1,500 \\
\hline
\end{tabular}

* 28\% of total area surveyed;

** $30 \%$ resampling of surveyed plots;

$* * *$ Transportation of helicopter and pilot to study area;

$\checkmark$ Labour field assistants;

,, Transportation by car between sample plots during field work. 
from year to year:

$$
\mathrm{N}_{\mathrm{t}+1}=\mathrm{N}_{\mathrm{t}} \times \lambda \mathrm{t}-\mathrm{H}_{\mathrm{t}}
$$

where $\lambda_{t}$ is the growth rate (varying stochastically see below) in year $t$, and $\mathrm{H}_{\mathrm{t}}$ is the number of moose harvested in year t. We characterised the annual population growth rate using two long-term studies, and calculated it annually as the ratio of the preharvest population size and the post-harvest population size from the previous year. Over 33 years the moose population in the Grimsö wildlife research area in Sweden had a mean growth rate of $\mu_{\lambda}=1.42$ and a standard deviation of $\sigma_{\lambda}=0.097$ (Rönnegård et al. 2008). Over 27 years in Nordland in Norway, the mean growth rate was $\mu_{\lambda}=1.39$ and the standard deviation $\sigma_{\lambda}=0.10$ (Solberg \& Sæther 1999). Both moose populations were strongly affected by hunting, e.g. causing a skewed sex-ratio (Milner et al. 2007). The mean harvest rates were 0.37 and 0.34 for the Grimsö and Nordland populations, respectively, and $>90 \%$ of the mortality in adults was due to hunting (Solberg \& Sæther 1999, Rönnegård et al. 2008). Furthermore, there were no predators present during the study period. The high proportion of females and the lack of predators increased the mean growth rates compared to a population in which random hunting strategies are applied and in which natural predators are available (Milner et al. 2007). The two populations showed similar growth rates as found in other Scandinavian populations (Stubsjøen et al. 2000, Gaillard 2007). Analyses of the data showed little evidence of density dependence $(r=0.20, P=0.34$ for the Norway data, and $\mathrm{r}=0.14, \mathrm{P}=0.45$ for the Grimsö data), though the growth rate may be influenced by winter snow depth and summer temperature (Solberg et al. 1999). We assumed that the annual growth rates $\left\{\lambda_{t}, t=0,1, \ldots\right\}$ were independent and identically distributed normal random variables with a mean of $\mu_{\lambda}=1.4$ and a standard deviation of $\sigma_{\lambda}=0.1$.

\section{Moose harvest}

We assumed that the managers used a proportional threshold harvest strategy. Our intention was to maintain the population within the acceptable range of sizes (between 800 and 1,200):

$$
\mathrm{H}_{\mathrm{t}}= \begin{cases}0, & \text { if } \quad \overline{\mathrm{N}}_{\mathrm{t}} \leq 400 \\ 0.7\left(\mu_{\lambda}-1\right) \overline{\mathrm{N}}_{\mathrm{t}}, & \text { if } \quad 400<\overline{\mathrm{N}}_{\mathrm{t}}<800 \\ \left(\mu_{\lambda}-1\right) \overline{\mathrm{N}}_{\mathrm{t}}, & \text { if } \quad 800 \leq \overline{\mathrm{N}}_{\mathrm{t}} \leq 1200 \\ 1.3\left(\mu_{\lambda}-1\right) \overline{\mathrm{N}}_{\mathrm{t}}, & \text { if } \quad \overline{\mathrm{N}}_{\mathrm{t}}>1200 .\end{cases}
$$

where $\overline{\mathbf{N}}_{\mathrm{t}}$ is the estimated moose population size in year $t$ (the mean of the probability distribution). The harvest strategy attempts to remove the expected net increase in the population in year $t$, when the population size is within the acceptable bounds. When the population is estimated to be unacceptably high, the harvest is increased, and the harvest rate is decreased when the population is estimated to be unacceptably low. If the expected population size is below 400 individuals, then no harvest takes place. This is broadly how moose have been harvested over the last 30 years in Scandinavia (Lavsund et al. 2003). Finally, we assumed that the entire quota is successfully taken, remembering that the quota will be set by inaccurate estimates of the real number.

\section{Simulated moose management}

The structure of our simulated moose management and dynamics is outlined in Figure 2. Across different runs, we tested different combinations of survey methods (Table 3). The first strategy is not to monitor at all, but to harvest 400 individuals annually. This harvest quota is the deterministic maximum sustainable yield for a population of 1,000 moose and would maintain the population at this target level in the absence of measurement error and variability in growth rate. The second strategy assumes perfect knowledge of the moose population size after the hunting period has finished and before reproduction (February-May). This provides an upper bound on performance for all other monitoring strategies. It is not possible to maintain the population at 1,000 individuals even when the population size is known perfectly in FebruaryMay, due to the variability in the moose population growth rate. Strategies 3-8 are fixed combinations of survey methods to be conducted over time. Strategies 9-11 are state dependent; i.e. the survey methods used each year depend on the predicted population size and its relationship to the objective. In each case, the manager chooses a low-reliability survey method when the population is expected to be within the accepted bounds, since there is a low risk of an unacceptable population size next year. When the population size is thought to be unacceptably small or large, then a more accurate survey method is selected to ensure that an appropriate harvest quota is set, thus maximising the probability of an acceptable population size in the future.

For each monitoring strategy, we constructed 500 independent simulations. Each run represents 20 


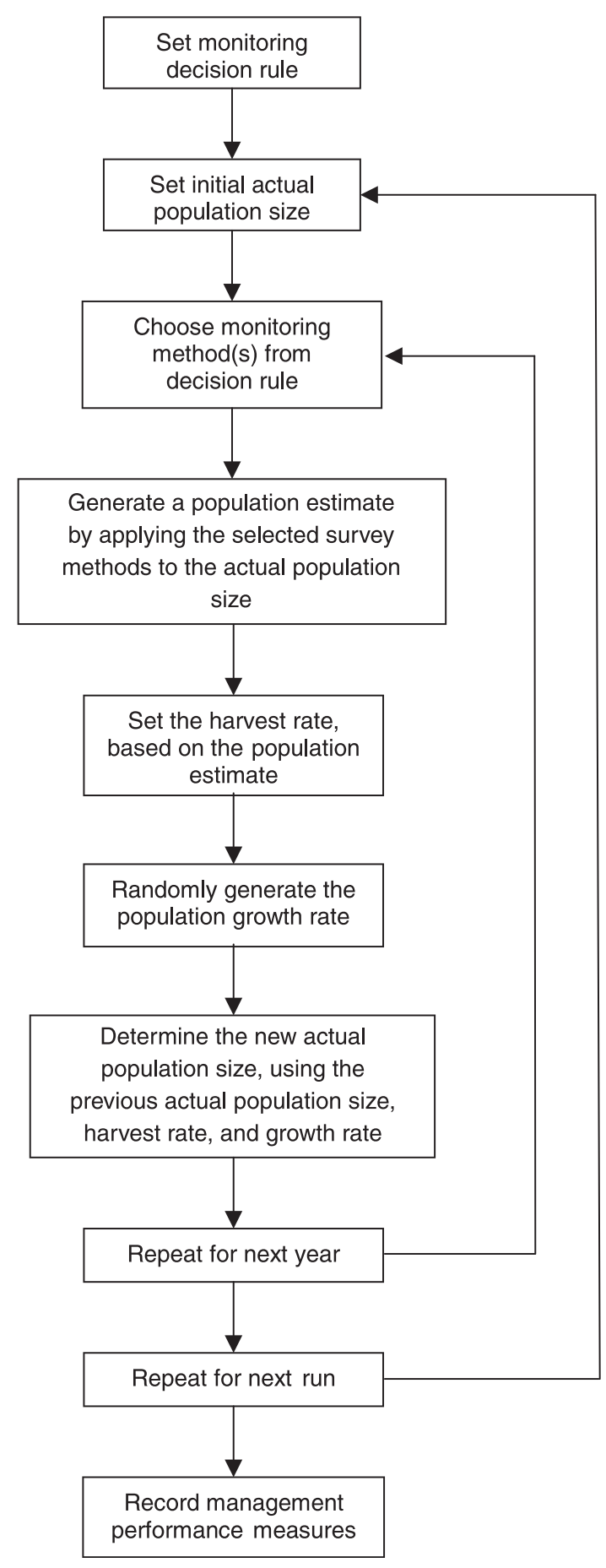

Figure 2. Flow chart describing the process of simulating moose monitoring and management.

years of moose management, simulating the actual moose population dynamics as well as the imperfect observations and decisions made by the manager. At the beginning of each run, the actual moose pop-
Table 3. Description of the monitoring strategies used in the simulation process.

\begin{tabular}{|c|c|}
\hline No & Strategy \\
\hline 1 & $\begin{array}{l}\text { No monitoring, with a harvest of } 400 \text { individuals taken } \\
\text { annually }\end{array}$ \\
\hline 2 & Perfect knowledge of the February population size \\
\hline 3 & An aerial survey is conducted each year \\
\hline 4 & Pellet-group counts are conducted each year \\
\hline 5 & Hunters' observations are recorded each year \\
\hline 6 & $\begin{array}{l}\text { Pellet-group counts and hunters' observations are } \\
\text { combined each year }\end{array}$ \\
\hline 7 & $\begin{array}{l}\text { An aerial survey is conducted every } 4 \text { th year, with } \\
\text { pellet-group counts each other year }\end{array}$ \\
\hline 8 & $\begin{array}{l}\text { An aerial survey is conducted every } 4 \text { th year, with } \\
\text { hunters' observations each other year }\end{array}$ \\
\hline 9 & $\begin{array}{l}\text { An aerial survey is used in the first year; otherwise: } \\
\text { - If } 950<\overline{\mathrm{N}}_{\mathrm{t}}<1050^{\mathrm{a}} \text {, } \\
\text { then hunters' observations are used } \\
\text { - If } 850<\overline{\mathrm{N}}<950^{\mathrm{a}} \text { or } \\
1050<\overline{\mathrm{N}}_{\mathrm{t}}<1150^{\mathrm{a}} \text {, } \\
\text { then pellet-group counts are used; } \\
\text { - If } \overline{\mathrm{N}}_{\mathrm{t}}<850^{\mathrm{a}} \text { or } \\
\overline{\mathrm{N}}_{\mathrm{t}}>1150^{\mathrm{a}} \text {, then aerial surveys are used. }\end{array}$ \\
\hline 10 & $\begin{array}{l}\text { An aerial survey is used in the first year; otherwise: } \\
\text { - If } 300<\overline{\mathrm{N}}_{\mathrm{t}}<500^{\mathrm{a}}, 700<\overline{\mathrm{N}}_{\mathrm{t}}<900^{\mathrm{a}} \text { or } \\
1100<\overline{\mathrm{N}}_{\mathrm{t}}<1300^{\mathrm{a}} \text {, an aerial survey is used; } \\
\text { - For all other } \overline{\mathrm{N}}_{\mathrm{t}} \text {, pellet-group counts are used. }\end{array}$ \\
\hline 11 & $\begin{array}{l}\text { An aerial survey is used in the first year; otherwise: } \\
\text { - If } 350<\overline{\mathrm{N}}_{\mathrm{t}}<450^{\mathrm{a}}, 750<\overline{\mathrm{N}}_{\mathrm{t}}<850^{\mathrm{a}} \text {, or } \\
1150<\overline{\mathrm{N}}_{\mathrm{t}}<1250^{\mathrm{a}} \text {, an aerial survey is used; } \\
\text { - For all other } \overline{\mathrm{N}}_{\mathrm{t}}^{\mathrm{a}} \text {, pellet-group counts are used. }\end{array}$ \\
\hline
\end{tabular}

${ }^{a} \mathrm{~N}_{\mathrm{t}}=\mu \lambda \overline{\mathrm{N}}_{\mathrm{t}-1}-\mathrm{H}_{\mathrm{t}-1}$ is the expected current population size, using the mean annual growth rate, the expected population size in the previous year, and the known harvest taken in the previous year.

ulation size is set to 1,000 individuals (see Fig. 2). After this initialisation, the survey method is chosen using the strategies described in Table 3 . We drew imperfect population estimates, based on the true population size, according to the reliability of the chosen survey methods. We combined these estimates using Bayes' theorem, and the mean of the posterior distribution is used as the best estimate of current population size, $\overline{\mathrm{N}}_{\mathrm{t}}$. We next set the harvest quota, using the harvest rule in equation 2), based on $\overline{\mathrm{N}}_{\mathrm{t}}$. With the manager's harvest decision made, the moose population undergoes random growth according to the population model and the harvest quota is applied, generating a new actual moose population size (see equation 1). The simulation reverts back to the monitoring decision rule, where survey, decision-making and population dynamics are repeated for the duration of the run. As all the runs are completed, we recorded a variety of statis- 
Table 4. Management performance and cost for the monitoring strategies (see Table 2). Mean (in italics) and 2.5 and 97.5 percentiles are shown in brackets.

\begin{tabular}{llccccr}
\hline $\begin{array}{l}\text { Monitoring } \\
\text { strategy }\end{array}$ & $\begin{array}{c}\text { Proportion of time } \\
\text { inside interval }\end{array}$ & $\begin{array}{c}\text { Proportion of time } \\
\mathrm{N}<800\end{array}$ & $\begin{array}{c}\text { Proportion of time } \\
\mathrm{N}>1200\end{array}$ & $\begin{array}{c}\text { Annual } \\
\text { harvest }\end{array}$ & $\begin{array}{c}\text { Within-run } \\
\text { S.D. (Harvest) }\end{array}$ & Cost in $€$ \\
\hline 1 & $0.18(0,0.5)$ & $0.44(0,0.95)$ & $0.38(0,0.95)$ & 400 & 0 & 0 \\
2 & $0.81(0.55,1.00)$ & $0.11(0,0.4)$ & $0.08(0,0.3)$ & 394 & 89 & 0 \\
3 & $0.72(0.35,0.95)$ & $0.18(0,0.55)$ & $0.10(0,0.45)$ & 390 & 133 & 27000 \\
4 & $0.69(0.35,0.95)$ & $0.21(0,0.6)$ & $0.10(0,0.4)$ & 387 & 147 & 8400 \\
5 & $0.66(0.35,0.95)$ & $0.23(0,0.6)$ & $0.11(0,0.4)$ & 387 & 161 & 1600 \\
6 & $0.76(0.45,1.00)$ & $0.15(0,0.5)$ & $0.08(0,0.35)$ & 392 & 124 & 10000 \\
7 & $0.70(0.3,0.95)$ & $0.21(0,0.6)$ & $0.09(0,0.4)$ & 386 & 143 & 13100 \\
8 & $0.67(0.3,0.9)$ & $0.23(0,0.65)$ & $0.10(0,0.4)$ & 384 & 154 & 7900 \\
9 & $0.70(0.4,0.95)$ & $0.19(0,0.55)$ & $0.10(0,0.4)$ & 390 & 145 & $15100(10500,19000)$ \\
10 & $0.73(0.35,0.6)$ & $0.18(0,0.6)$ & $0.09(0,0.35)$ & 388 & 137 & $19000(15000,22500)$ \\
11 & $0.71(0.35,0.95)$ & $0.19(0,0.6)$ & $0.10(0,0.35)$ & 387 & 143 & $13900(11200,17800)$ \\
\hline
\end{tabular}

tics that indicate management performance (Table 4 and 5). Milner-Gulland et al. (2001) used a similar strategy for testing the effect of different harvesting strategies on saiga antelope Saiga tatarica.

\section{Results}

\section{Maintaining acceptable population size}

Subject to the harvest strategy (see equation 2) and with perfect observation of the February population size, the moose population was of an acceptable size $(800<\mathrm{N}<1,200)$ on an average of 16.2 years ( \pm 2.6 ) out of 20 years (strategy 2; see Table 4). Subject to the imperfect monitoring strategies, the number of years in which the moose population was of acceptable size varied from 9.6 to 15.2 years. The strategies that best maintained the population at an acceptable size were a combination of pellet-group counts and hunters' observations every year (i.e. strategy 6), a state dependent survey combining aerial surveys and pellet-group counts (strategy 10), and annual aerial surveys (strategy 3; see Table 4). These strategies kept the moose population within the management goal of, on average, 14.4-15.2 out of 20 years.

The mean proportion of time in which the moose population was too small $(\mathrm{N}<800)$ was always longer than the proportion of time the moose population was too large ( $\mathrm{N}>1200$; see Table 4).

The improvement in substituting pellet count (strategy 4) or hunters' observation (strategy 5) with aerial survey every fourth year was low (strategy 7 and 8). In both cases, the proportion of time that the moose population was of acceptable size only increased by $1 \%$ (compare strategy 4 to 7 and strategy 5 to 8 ; see Table 4). However, the mean annual cost increased significantly: the difference between strategies 4 and 7 (pellet count) was almost $4,700 €$ per annum, the difference between strategy 5 and 8 (hunter's observation) was $6,300 €$ per annum.

The proportion of time that the moose population was of acceptable size tended to increase with monitoring costs (strategies 3-11; Fig. 3A). An annual combination of pellet group counts and hunters' observations (strategy 6) performed well with respect to both cost and achieving an appropriate remaining population size (see Fig. 3A).

By managing the moose population with a constant harvest of 400 moose (assuming a constant deterministic population growth for the starting population of 1,000 , strategy 1 ; see Table 3 ) it took on average 4.5 years before the moose population was unacceptably small $(\mathrm{N}<800)$ or large $(\mathrm{N}>$ 1,200; see Table 4). Furthermore, with a constant

Table 5. Mean proportion (2.5, 97.5 percentiles) of time the different monitoring methods were used in the state dependent monitoring strategies (9-11).

\begin{tabular}{lccc}
\hline $\begin{array}{l}\text { Monitoring } \\
\text { strategy }\end{array}$ & Aerial survey & $\begin{array}{c}\text { Pellet-group } \\
\text { counts }\end{array}$ & $\begin{array}{c}\text { Hunters' } \\
\text { observation }\end{array}$ \\
\hline 9 & $0.39(0.20,0.60)$ & $0.43(0.20,0.65)$ & $0.18(0,0.35)$ \\
10 & $0.56(0.35,0.75)$ & $0.44(0.25,0.65)$ & - \\
11 & $0.29(0.15,0.50)$ & $0.71(0.5,0.85)$ & - \\
\hline
\end{tabular}


Figure 3. Relationships between the proportion of time within the moose management goal and the annual cost of monitoring (A) and the year-to-year variation in moose harvest and annual cost (B). The dashed line indicates performance with perfect knowledge of moose population after the hunting season and before reproduction (i.e. Strategy 2).
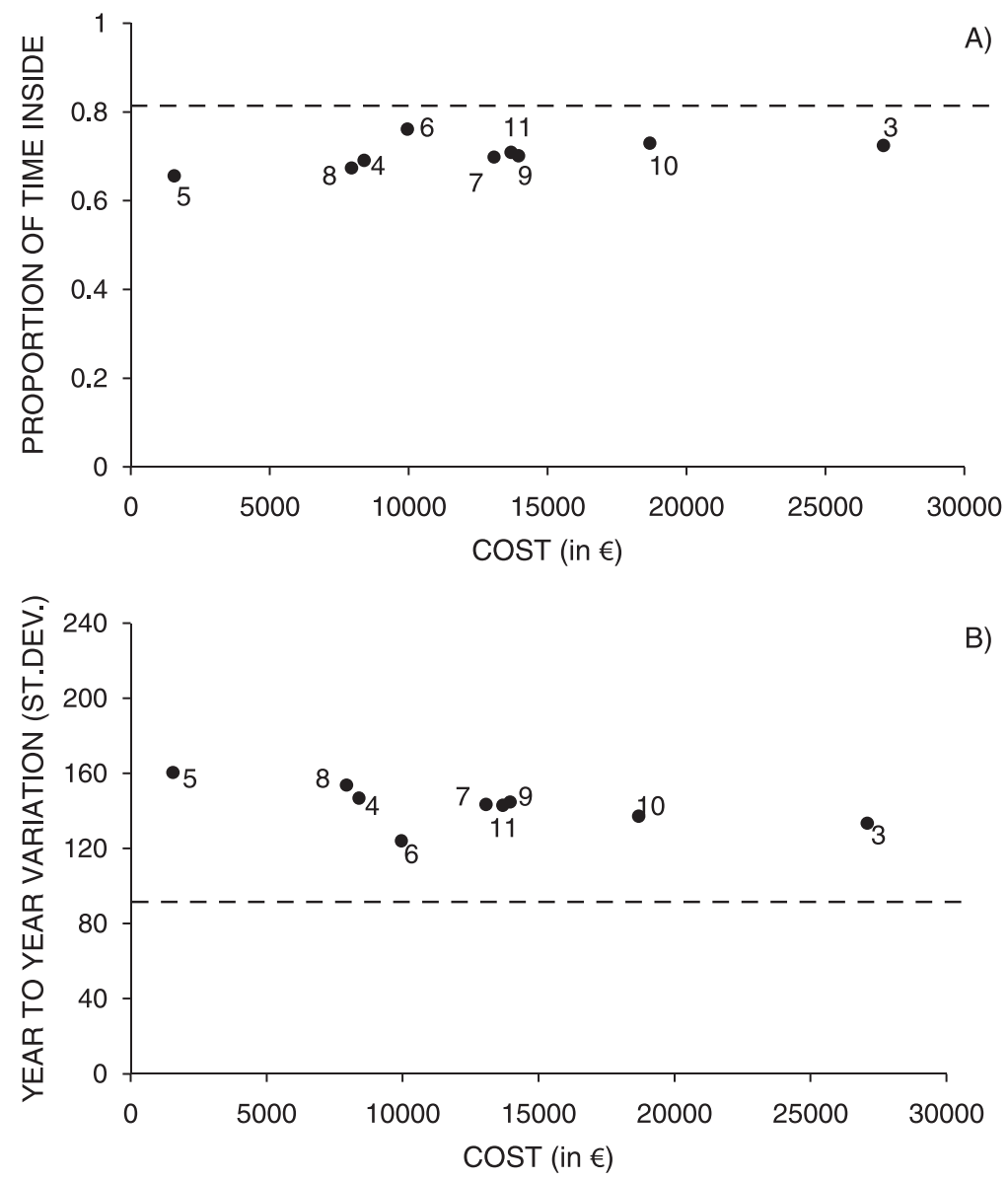

harvest, the moose population rarely returned to an acceptable size and the proportion of time during which the moose population was of acceptable size was, therefore, also low; in average 3.6 out of 20 years (strategy 1 ; see Table 4).

\section{Harvest}

The mean annual harvest varied between 384 and 392 moose across the monitoring strategies, which is close to the maximum sustainable deterministic harvest of 400 individuals assuming a fixed population size $(1,000$ post-harvest population size and $\lambda$ $=1.40)$. The two best monitoring strategies with respect to variation in annual harvest were combined annual pellet counts and hunters' observations (strategy 6) followed by annual aerial survey (strategy 3; see Table 4). There tended to be a negative relationship between variation in harvest and monitoring cost (see Fig. 3B).

\section{Discussion}

The trade-off between the cost and accuracy of a survey method is a general and important question for a broad range of population management practices. We have only recently begun exploring this trade-off in conservation biology (Nalle et al. 2004, Polasky et al. 2008) and for harvested populations (Gordon et al. 2004, Hauser et al. 2006).

Through our simulations, we found that better management performance generally meant increasing monitoring costs (see Fig. 3). However, our results suggest that a combination of two relatively inexpensive survey methods can substantially improve the outcome of management at a relatively low cost. For example, the combination of the hunters' observations and pellet-group counts every year (strategy 6;10,000€/annum) gave better performance than annual aerial surveys (strategy $3 ; 27,000 € /$ annum), incurring about one third of the 
cost. In our simulations of moose management, we found that by combining the hunters' observations with pellet-group counts, the proportion of years with the preferred number of moose increased from 66 to $76 \%$ and the costs increased from $1,600 €$ (hunters' observation) to $10,000 €$. The state-dependent monitoring strategies (strategies 9-11; see Table 3) did not differ substantially from other strategies with respect to any of the performance measures. Restricting the states that triggered expensive monitoring decreased the cost significantly while maintaining almost equal performance (compare strategies 10 and 11; see Table 4).

Even when we had perfect knowledge of the moose population size in February, the moose population size was outside the desirable range 19\% of the time. These failures occur because the monitoring is conducted after the hunting season but before reproduction. There is a considerable variation in net growth (reproduction and summer survival) between years and that may bring the population outside the desirable limits. Therefore, survey methods that could be conducted just before the hunting season, e.g. distance sampling that estimates density, recruitment (e.g. juveniles/female) and sex structure (Buckland et al. 2001) may improve management performance in populations even when there is considerable inter-annual variation in reproduction and survival. Also, the use of the distance sampling technique in combination with aerial counts may in the future lower the cost of aerial surveys (approximately $50 \%$ of the cost of sample plot technique) without losing accuracy according to preliminary studies (Hörnell-Willebrand \& Pehrson 2010). The expense of implementing e.g. distance sampling should preferably be weighed against the improved information that they offer in the future, as we have done for other survey methods in this study.

In the simulations, the moose population was more likely unacceptably small than being unacceptably large (see Table 4). This is due to the harvest strategy, where it takes longer to recover a small population than to reduce a large population until it is of an acceptable size.

Estimating abundance of wildlife populations with acceptable accuracy is difficult (Morellet et al. 2007). We rarely have true values or estimates from 'gold standard' methods (e.g. capture-mark-recapture; Buckland et al. 2001) to compare our density estimates with. Thus, a wide range of indices of wildlife population size and impact are commonly used in wildlife management (Williams et al. 2001, Morellet et al. 2007). However, indices need to be converted into absolute numbers when management (i.e. quotas) and performance are measured in absolute numbers (e.g. minimum viable population size for conservation and hunting quotas for harvested populations). This transformation may follow a linear or non-linear relationship (Morellet et al. 2007). In our study, we used linear relationships between indices and population size supported by data in a few restricted studies (see Appendix I). However, such relationships probably vary due to temporal and spatial scale (Ericsson \& Wallin 1999) and studied species (Thompson et al. 1998). Therefore, it will be important to further study these relationships and validate the models each time they are used. Regardless of the survey method, all estimates of population size are surrounded by some level of uncertainty, and we have found that the management performance might be increased by utilising several low cost and high uncertainty survey methods. Morellet et al. (2007) similarly proposed that multiple indicators and indices (not only for population abundance but also e.g. habitat quality and body mass) should be used to strengthen the performance of management.

It is important to note that the quantitative performance levels that we give here are related to the modelled and simulated moose population and not to the moose located in the actual study area. The relationship between pellet-group counts and population size has not been investigated thoroughly for the study area and the model used here; similarly all statistical models are not perfect. Extreme non-linearity in the relationship between population indices and population size that were not detected in our study could alter our ranking of monitoring strategies if they were indeed present. Furthermore, the annual population growth rate was characterised by using two long-term studies from Scandinavia. The population growth rates in the two populations were similar to other populations in Scandinavia both regarding mean growth rate and inter-annual variation in survival and reproduction (Stubsjøen et al. 2000, Gaillard 2007). However, lower population growth rates and interannual variation has also been evident in other moose populations (Sæther et al. 2007, Boertje et al. 2009). Thus, to improve moose management and reduce the probability of getting populations of 'undesirable' size, one has to develop monitoring methods that capture inter-annual variation in 
growth rate and harvest strategies that are related to the possibilities to detect these inter-annual variation. Very sophisticated harvest strategy will not work with poor monitoring methods.

We have used a fairly simple population model without density dependence and age and sex structure. However, the mean and variance in growth rate used to describe the changes in the moose population were from two quite different areas in Scandinavia and neither population showed any indication of a density-dependent growth rate (Solberg \& Sæther 1999, Rönnegård et al. 2008). Therefore, we expect that the moose population model is appropriate for Scandinavia and these densities are well below the densities that might trigger negative density dependence. The lack of age and sex structure in the moose population might affect the relative performances of the monitoring strategies. Including age and sex structure could increase our ability to predict the annual variation in reproduction within the wildlife populations. Thus, direct observations (e.g. aerial counts, hunters' observations and distance sampling) should perform relatively better than pellet-group counts, if age and sex structure information were included. Moreover, the actual performance may be better than the results that we recorded here, since management can behave adaptively during a hunting season. For example, harvest quotas within moose management units are sometimes not fulfilled because the moose hunters find a divergence from the anticipated conditions e.g. calf/cow index (J. Wikland, pers. comm., Örebro county board) or it may be difficult for hunters to find moose to harvest, if the real numbers are low. Such circumstances would bring further uncertainty to management. A more appropriately reactive harvest strategy could be developed in concert with a sex and age-structured population model, but would require a more elaborate model linking of the hunters' observations to actual population size. However, our main aim was to describe the relative performance of the different monitoring strategies and to relate them to the monitoring costs. The harvest strategy and management goals were fixed to simple rules that broadly reflect current moose management. However, as shown here, there is scope for other studies to explore different population models, management objectives and harvesting rules.

Wild large herbivores provide values and incomes, but also have a major impact on land use; therefore, it could be costly to be above the limit due to overbrowsing, but it could also be costly to be below, as it takes more time to regain population size and harvest quotas (Gordon et al. 2004, Mysterud 2006). For moose, forest damage and moose-vehicle collisions are the main costs whereas the value of moose meat and moose hunting licenses are the main financial benefits (Mattsson 1990, Seiler 2003, Ingemarson et al. 2007). After setting the management goals, the costs and measurement errors associated with each survey method should be included when deciding which method should be used. The annual monitoring costs in our study varied between 1,600 and $27,000 €$. As a comparison, the value of moose hunting in Sweden was estimated at $140,000,000 €$ (Mattsson 1990, Mattsson et al. 2007a, 2007b), or approximately $560,000 €$ for 400 harvested moose. The cost of forest damage, road safety and traffic accidents caused by moose and roe deer Capreolus capreolus has been estimated at 200,000,000€ in Sweden (Loman 2004, Ingemarson et al. 2007). Even though these estimates are crude, they indicate that the monitoring costs are small relative to the other costs and benefits of moose management. Furthermore, underharvesting and overharvesting might have different implications for the society. It is impossible to consistently maintain a point-value target population size, even under perfect observations. Instead, we can define a range of population sizes which are considered acceptable. Setting an acceptable interval around this target should incorporate the costs and benefits incurred by population management and fulfill the demands of all relevant interest groups.

\section{Management implications}

In wildlife management, managers have often aimed at using the best available monitoring method without considering the monitoring costs and risk of not achieving the management goals. The main conclusion in our paper is that the combination of two relatively cheap monitoring methods performed as well as or even better than a single accurate and expensive method. Thus, selecting monitoring methods should include assessments of the cost of the monitoring methods and the cost of making bad management decisions.

Acknowledgements - our work was supported by grants from The Swedish Environmental Protection Agency (research programme 'Adaptive management of fish and wildlife populations'), the forest company Sveaskog, the 
Australian Research Council and a Commonwealth Environmental Research Facility large hub grant. Henrik Andrén was supported by STINT and Johan Månsson was supported by the Swedish University of Agricultural Sciences (SLU) for visiting the Ecology Centre at University of Queensland and Cindy E. Hauser was supported by SLU for visiting Grimsö. We thank R. Bergström, P. Kjellander, M. Garel, A. Mysterud and an anonymous reviewer for valuable comments, and $\mathrm{M}$. McCarthy for helpful discussions of the model structure.

\section{References}

Anonymous 2007: En bättre viltförvaltning med inriktning på älg. - Commision of inquiry's recommendation of future moose management, SOU 2007: 63. (In Swedish).

Andersen, R., Hjeljord, O. \& Sæther, B-E. 1992: Moose defecation rates in relation to habitat quality. - Alces 28: 95-100.

Barnes, R.F.W. 2001: How reliable are dung counts for estimating elephant numbers? - African Journal of Ecology 39: 1-9.

Boertje, R.D., Keech, M.A., Young, D.D., Kellie, K.A. \& Seaton, C.T. 2009: Managing for elevated yield of moose in interior Alaska. - Journal of Wildlife Management 73(3): 314-327.

Bowden, D.C., White, G.C. \& Bartmann, R.M. 2000: Optimal allocation of sampling effort for monitoring a harvested mule deer population. - Journal of Wildlife Management 64: 1013-1024.

Buckland, S.T., Anderson, D.R., Burnham, K.P., Laake, J.L., Borchers, D.L. \& Thomas, L. 2001: Introduction to distances sampling - estimating abundance of biological populations. - Oxford University press, New York, New York, USA, $440 \mathrm{pp}$.

Campbell, D., Swanson, G.M. \& Sales, J. 2004: Comparing the precision and cost-effectiveness of faecal pellet group count methods. - Journal of Applied Ecology 41: 11851196.

Caughley, G. \& Sinclair, A.R.E. 1994: Wildlife ecology and management. - Blackwell Science, Oxford, UK, 334 pp.

Chades, I., McDonald-Madden, E., McCarthy, M.A., Wintle, B., Linkie, M. \& Possingham, H.P. 2008: When to stop managing or surveying cryptic threatened species. - In: Levin, A.S. (Ed.); Proceedings of the National Academy of Sciences of the United States of America 105: 13936-13940.

Ericsson, G. \& Wallin, K. 1999: Hunter observations as an index of moose Alces alces population parameters. Wildlife Biology 5(3): 177-185.

Garel, M., Cugnasse, J-M., Loison, A., Gaillard, J-M., Vuiton, C. \& Maillard, D. 2005: Monitoring the abundance of mouflon in South France. - European Journal of Wildlife Research 51: 69-76

Gaillard, J-M. 2007: Are moose only a large deer: some life history considerations. - Alces 43: 1-11.

Gerber, L.R., Beger, M., McCarthy, M.A. \& Possingham,
H.P. 2005: A theory for optimal monitoring of marine reserves. - Ecology Letters 8: 829-837.

Gordon, I.J., Hester, A.J. \& Festa-Bianchet, M. 2004: The management of wild herbivores to meet economic, conservation and environmental objectives. - Journal of Applied Ecology 41(6): 1021-1031.

Haagenrud, H., Krzysztof, M., Kaarlo, N. \& Stålfelt, F. 1987: Management of moose in Nordic countries. Swedish Wildlife Research (Suppl. 1): 635-642.

Hauser, C.E. \& McCarthy, M.A. 2009: Streamlining 'search and destroy': cost-effective surveillance for invasive species management. - Ecology Letters 12: 683-692.

Hauser, C.E., Pople, A.R. \& Possingham, H.P. 2006: Should managed populations be monitored every year? Ecological Applications 16: 807-819.

Hörnell-Willebrand, M. \& Pehrson, Å 2010: Jämförelse av tre inventeringsmetoder för älg. - Slutrapport forskningsprojekt, Naturvårdsverket, Stockholm, Sweden, 23 pp. (In Swedish)

Ingemarson, F., Claesson, S. \& Thuresson, T. 2007: Älgoch rådjursstammarnas kostnader och värden. (In Swedish with an English summary: Costs and benefits of moose and roe deer populations). - Report 3, Swedish forest agency, Jönköping, Sweden, 60 pp.

Jachmann, H. 2002: Comparison of aerial counts with ground counts for large African herbivores. - Journal of Applied Ecology 39: 841-852.

Jordan, P.A., Peterson, R.O., Campbell, P. \& McLaren, B. 1993: Comparsion of pellet counts and aerial counts for estimating density of moose at Isle Royale: a progress report. - Alces 29: 267-278.

Kindberg, J., Ericsson, G. \& Swenson, J.E. 2009: Monitoring rare or elusive large mammals using effortcorrected voluntary observers. - Biological conservation 142: $159-165$

Loman, J-O. 2004: Statistical yearbook of forestry 2004. National board of forestry, Jönköping, Sweden, 329 pp. (In Swedish with an English summary).

Lavsund, S., Nygren, T. \& Solberg, E.J. 2003: Status of moose populations and challenges to moose management in Fennoscandia. - Alces 39: 109-130.

Mandujano, S. \& Gallina, S. 1995: Comparison of deer censusing methods in tropical dry forest. - Wildlife Society Bulletin 23: 180-186.

Mattsson, L. 1990: Moose management and the economic value of hunting. - Scandinavian Journal of Forest Research 5: 575-581.

Mattsson, L., Boman, M. \& Ericsson, G. 2007a: Jakten i Sverige - ekonomiska värden och attityder jaktåret 2005/ 2006. - Report, Swedish University of Agricultural Sciences, Umeå, Sweden, 24 pp. (In Swedish).

Mattsson, L., Boman, M., Ericsson, G., Paulrud, A., Laitila, T., Kriström, B. \& Brännlund, R. 2007b: Welfare foundations for efficient management of wildlife and fish resources for recreational use in Sweden. - In: Lovelock, B. (Ed.); Tourism and the consumption of wildlife: Hunting, shooting and sport fishing. Routledge, London, UK, pp. 169-182.

McIntosh, R., Burlton, F.W.E. \& McReddie, G. 1995: 
Monitoring the density of a roe deer Capreolus capreolus population subjected to heavy hunting pressure. - Forest Ecology and Management 79: 99-106.

Milner-Gulland, E.J., Shea, K., Possingham, H.P., Coulson, T. \& Wilcox, C. 2001: Competing harvesting strategies in simulated population under uncertainty. Animal Conservation 4: 157-167.

Milner, J.M., Nilsen, E.B. \& Andreassen, H.P. 2007: Demographic side effects of selective hunting in ungulates and carnivores. - Conservation Biology 21: 36-47.

Morellet, N., Gaillard, J-M., Hewison, A.J.M., Ballon, P., Boscardin, Y., Duncan, P., Klein, F. \& Maillard, D. 2007: Indicators of ecological change: new tools for managing populations of large herbivores. - Journal of Applied Ecology 44: 634-643.

Mysterud, A. 2006: The concept of overgrazing and its role in management of large herbivores. - Wildlife Biology 12(2): 129-141

Månsson, J., Andrén, H., Pehrson, Å \& Bergström, R. 2007: Moose browsing and forage availability - a scaledependent relationship? - Canadian Journal of Zoology 85: 372-380.

Nalle, D.J., Montgomery, C.A., Arthur, J., Polasky, S. \& Schumaker, N.H. 2004: Modeling joint production of wildlife and timber. - Journal of Environmental Economics and Management 48: 997-1017.

Neff, D.J. 1968: The pellet-group count technique for big game trend, census, and distribution: a review. - Journal of wildlife management 32: 597-614.

Polasky, S., Nelson, E., Camm, J., Csuti, B., Fackler, P., Lonsdorf, E., Montgomery, C., White, D., Arthur, J., Garber-Yonts, B., Haight, R., Kagan, J., Starfield, A. \& Tobalske, C. 2008: Where to put things? Spatial land management to sustain biodiversity and economic returns. - Biological conservation 141: 1505-1524.

Rönnegård, L., Sand, H., Andrén, H., Månsson, J. \& Pehrson, A 2008: Evaluation of four methods used to estimate population density of moose Alces alces. Wildlife Biology 14(3): 358-371.

Rout, T.M., Salomon, Y.\& McCarthy, M.A. 2009: Using sighting records to declare eradication of an invasive species. - Journal of Applied Ecology 46(1): 110-117.

Sæther, B-E., Engen, S., Solberg, E.J. \& Heim, M. 2007: Estimating the growth of a newly established moose population using reproductive value. - Ecography 30: 417-421.

Seiler, A. 2003: The toll of the automobile: wildlife and roads in Sweden. - PhD thesis, Swedish University of Agricultural Sciences, Uppsala, Sweden, 48 pp.

Smits, C.M.M., Ward, R.M.P. \& Larsen, D.G. 1994 Helicopter or fixed-wing aircraft: a cost-benefit analysis for moose surveys in Yukon Territory. - Alces 30: 45-50.

Solberg, E.J. \& Sæther, B-E. 1999: Hunter observations of moose Alces alces as a management tool. - Wildlife Biology 5(2): 107-117.

Solberg, E.J., Sæther, B-E., Strand, O. \& Loison, A. 1999: Dynamics of a harvested moose population in a variable environment. - Journal of Animal Ecology 68: 186-204.

Stubsjøen, T.S., Sæther, B-E., Solberg, E.J., Heim, M. \&
Rolandsen, C.H. 2000: Moose (Alces alces) survival in three populations in northern Norway. - Canadian Journal of Zoology 78: 1822-1830.

Sylvén, S. 2000: Effects of scale on hunter moose Alces alces observation rate. - Wildlife Biology 6(2): 157-165.

Thompson, W.L., Gowan, C. \& White, G.C. 1998: Monitoring vertebrate populations. - Academic press, London, UK, $365 \mathrm{pp}$.

Timmerman, H.R. 1974: Moose inventory methods: A review. - Naturaliste Canadien 101: 615-629.

Wennberg DiGasper, S. 2006: Already adaptive - an investigation of the performance of Swedish moose management organizations. - Lic. thesis, Luleå University of Technology, Luleå, Sweden, 133 pp.

Williams, B.K., Nichols, J.D. \& Conroy, M.J. 2001: Analysis and management of animal populations. Academic press, San Diego, USA, 817 pp.

Vincent, J-P., Hewison, A.J.M., Angibault, J-M. \& Cargnelutti, B. 1996: Testing density estimators on a fallow deer population of known size. - Journal of Wildlife Management 60: 18-28.

Yokomizo, H., Haccou, P. \& Iwasa, Y. 2004: Multiple-year optimization of conservation effort and monitoring effort for a fluctuating population. - Journal of Theoretical Biology 230: 157-171.

\section{Appendices}

\section{Appendix I. Linear relationships and system- atic sampling}

\section{Pellet-group counts}

The existing literature suggests that there is a linear relationship between pellet-group counts and other independent population size estimates (moose; Jordan et al. 1993, and deer and other ungulates; Barnes 2001). Furthermore, according to data collected by R. Bergström (pers. comm.), pelletgroup counts on six occasions in a 600 ha enclosure with known moose population size (varied between 0.8 and 5.2 moose $/ \mathrm{km}^{2}$ ) showed no difference in fit for linear or quadratic relationships $\left(\mathrm{R}^{2}\right.$ linear $=0.95$, $\mathrm{R}_{\text {quadratic }}^{2}=0.98$ with intercept and $\mathrm{R}^{2}=0.99$ for both models without intercept).

\section{Hunters' observations}

Using the raw data from Solberg \& Sæther (1999), we tested six different models (one linear and five non-linear) for the likely relationship between the hunters' observation and the moose population size. A linear relationship between the hunters' observations and the population size had an $\mathrm{R}^{2}$ of 0.58 . The quadratic relationship did not improve the fit $\left(\mathrm{R}^{2}=\right.$ 0.58). The relationship between $\log$ (hunters' observations) and the $\log$ (population size) had the highest 
$\mathrm{R}^{2}$ and was 0.60 . However, all models gave an estimate of moose numbers varying between 500 and 1,300 .

\section{Systematic sampling}

All three survey methods that we studied were based on systematic sampling. Systematic sampling gives an unbiased mean but the variance should only be treated as an approximation since it will only be unbiased if the animals are randomly distributed (Thompson et al. 1998).

\section{Appendix II. The relationship between indices and population size}

We have assumed that each population index, pellet-group counts and hunters' observations, have a linear relationship with population size in the following way: $\mathrm{I}=\mathrm{a}+\mathrm{b} \mathrm{N}+\varepsilon$,where $\mathrm{I}$ is the population index, $\mathrm{N}$ is the moose population size within $1,000 \mathrm{~km}^{2}$, and $\varepsilon$ is the noise in the relationship, assumed to be normally distributed with mean 0 and variance $\sigma_{\mathrm{I}}^{2}$. Therefore, the distribution of the index I given population size $\mathrm{N}$ has the normal distribution:

$$
f(I \mid N)=\frac{1}{\sqrt{2 \pi \sigma_{I}^{2}}} \exp \left[-\frac{(I-a-b N)^{2}}{2 \sigma_{I}^{2}}\right] .
$$

This is the probability distribution used to simulate the observed index of population size, given the true underlying moose population size.

When managers observe population size $\mathrm{N}$, they must construct a probability distribution for the likely population size $\mathrm{N}$, i.e. $\mathrm{f}(\mathrm{N} \mid \mathrm{I})$. This distribution can be found by combining the relationship B above with a prior distribution for population size. This probability distribution indicates the manager's sense of likely population size prior to monitoring this year. We assume that the manager has a normal prior distribution for population size $\mathrm{N}$, with mean $\mu_{\mathrm{N}}$ and variance $\sigma_{\mathrm{N}}{ }^{2}$ :

$$
f(N)=\frac{1}{\sqrt{2 \pi \sigma_{N}^{2}}} \exp \left[-\frac{\left(N-\mu_{N}\right)^{2}}{2 \sigma_{N}^{2}}\right] .
$$

Then the manager's posterior belief regarding population size can be obtained via Bayes' theorem:

$$
\begin{aligned}
& f(N \mid I)=\frac{f(I \mid N) f(N)}{\int_{N} f(I \mid N) f(N) d N} \\
& =\frac{\frac{1}{\sqrt{2 \pi \sigma_{I}^{2}}} \exp \left[-\frac{(\mathrm{I}-\mathrm{a}-\mathrm{bN})^{2}}{2 \sigma_{\mathrm{I}}^{2}}\right] \frac{1}{\sqrt{2 \pi \sigma_{\mathrm{N}}^{2}}} \exp \left[-\frac{\left(\mathrm{N}-\mu_{\mathrm{N}}\right)^{2}}{2 \sigma_{\mathrm{N}}^{2}}\right]}{\int_{-\infty}^{\infty} \frac{1}{\sqrt{2 \pi \sigma_{\mathrm{I}}^{2}}} \exp \left[-\frac{(\mathrm{I}-\mathrm{a}-\mathrm{bN})^{2}}{2 \sigma_{\mathrm{I}}^{2}}\right] \frac{1}{\sqrt{2 \pi \sigma_{\mathrm{N}}^{2}}} \exp \left[-\frac{\left(\mathrm{N}-\mu_{\mathrm{N}}\right)^{2}}{2 \sigma_{\mathrm{N}}^{2}}\right] \mathrm{dN}} \\
& =\frac{\frac{1}{2 \pi \sigma_{I} \sigma_{N}} \exp \left\{-\frac{\sigma_{I}^{2}+\sigma_{N}^{2} b^{2}}{2 \sigma_{I}^{2} \sigma_{N}^{2}}\left[N-\frac{\sigma_{N}^{2}(I-a) b+\sigma_{I}^{2} \mu_{N}}{\sigma_{I}^{2}+\sigma_{N}^{2} b^{2}}\right]^{2}-\frac{\left(I-a-b \mu_{N}\right)^{2}}{\sigma_{I}^{2}+\sigma_{N}^{2} b^{2}}\right\}}{\int_{-\infty}^{\infty} \frac{1}{2 \pi \sigma_{I} \sigma_{N}} \exp \left\{-\frac{\sigma_{I}^{2}+\sigma_{N}^{2} b^{2}}{2 \sigma_{I}^{2} \sigma_{N}^{2}}\left[N-\frac{\sigma_{N}^{2}(I-a) b+\sigma_{I}^{2} \mu_{N}}{\sigma_{I}^{2}+\sigma_{N}^{2} b^{2}}\right]^{2}-\frac{\left(I-a-b \mu_{N}\right)^{2}}{\sigma_{I}^{2}+\sigma_{N}^{2} b^{2}}\right\} d N} \\
& =\frac{1}{\sqrt{2 \pi \frac{\sigma_{I}^{2} \sigma_{N}^{2}}{\sigma_{I}^{2}+\sigma_{N}^{2} b^{2}}}} \exp \left\{-\frac{\sigma_{I}^{2}+\sigma_{N}^{2} b^{2}}{2 \sigma_{I}^{2} \sigma_{N}^{2}}\left[N-\frac{\sigma_{N}^{2}(\mathrm{I}-\mathrm{a}) \mathrm{b}+\sigma_{\mathrm{I}}^{2} \mu_{\mathrm{N}}}{\sigma_{\mathrm{I}}^{2}+\sigma_{\mathrm{N}}^{2} \mathrm{~b}^{2}}\right]^{2}\right\} \\
& =\frac{1}{\sqrt{2 \pi \frac{\left(\sigma_{I} / b\right)^{2} \sigma_{N}^{2}}{\left(\sigma_{I} / b\right)^{2}+\sigma_{N}^{2}}}} \exp \left\{-\frac{\left(\sigma_{I} / b\right)^{2}+\sigma_{N}^{2}}{2\left(\sigma_{I} / b\right)^{2} \sigma_{N}^{2}}\left[N-\frac{\sigma_{N}^{2}\left(\frac{I-a}{b}\right)+\left(\frac{\sigma_{I}}{b}\right)^{2} \mu_{N}}{\left(\sigma_{I} / b\right)^{2}+\sigma_{N}^{2}}\right]^{2}\right\} \text {. }
\end{aligned}
$$


So, the probability distribution of the plausible population sizes $\mathrm{N}$, given an observed index I, has a normal distribution with mean

$$
\mathrm{E}(\mathrm{N} \mid \mathrm{I})=\frac{\sigma_{\mathrm{N}}^{2}\left(\frac{\mathrm{I}-\mathrm{a}}{\mathrm{b}}\right)+\left(\frac{\sigma_{\mathrm{I}}}{\mathrm{b}}\right)^{2} \mu_{\mathrm{N}}}{\sigma_{\mathrm{N}}^{2}+\left(\frac{\sigma_{\mathrm{I}}}{\mathrm{b}}\right)^{2}}
$$

and variance

$$
\operatorname{var}(\mathrm{N} \mid \mathrm{I})=\frac{\sigma_{\mathrm{N}}^{2}\left(\frac{\sigma_{\mathrm{I}}}{\mathrm{b}}\right)^{2}}{\sigma_{\mathrm{N}}^{2}+\left(\frac{\sigma_{\mathrm{I}}}{\mathrm{b}}\right)^{2}} .
$$

We assume that the manager's prior information on population size is limited $\left(\sigma_{\mathrm{N}}^{2}\right.$ is large).

$$
\begin{aligned}
& \text { As } \sigma_{\mathrm{N}} \rightarrow \infty \\
& \mathrm{f}(\mathrm{N} \mid \mathrm{I}) \rightarrow \frac{1}{\sqrt{2 \pi\left(\sigma_{\mathrm{I}} / \mathrm{b}\right)^{2}}} \exp \left\{-\frac{[\mathrm{N}-(\mathrm{I}-\mathrm{a}) / \mathrm{b}]^{2}}{2\left(\sigma_{\mathrm{I}} / \mathrm{b}\right)^{2}}\right\},
\end{aligned}
$$

which is a normal distribution with mean (I - a)/b and standard deviation $\sigma_{\mathrm{I}} / \mathrm{b}$. We use this limiting distribution in the absence of other prior information. The parameters $\mathrm{a}, \mathrm{b}$, and $\sigma_{\mathrm{I}}$ are estimated separately for pellet group counts and hunter observations, with their values given in Table 1. 